\title{
The impact of seating location on black carbon exposure in public transit buses: Implications for vulnerable groups
}

\author{
Katharina Bauer ${ }^{\mathrm{a}}$, Thijs Bosker ${ }^{\mathrm{a}, \mathrm{b}}$, Kim N. Dirks ${ }^{\mathrm{c}}$, Paul Behrens ${ }^{\mathrm{a}, \mathrm{b}, *}$ \\ ${ }^{a}$ Leiden University College, Leiden University, P.O. Box 13228, 2501 EE The Hague, The Netherlands \\ ${ }^{\mathrm{b}}$ Institute of Environmental Sciences, Leiden University, P.O. Box 9518, 2300 RA Leiden, The Netherlands \\ ${ }^{\mathrm{c}}$ School of Population Health, University of Auckland, Private Bag 92019, Auckland Mail Centre, Auckland 1142, New Zealand
}

\section{A R T I C L E I N F O}

\section{Keywords:}

Black carbon

Public transit

Exposure concentration

Vulnerable passengers

\begin{abstract}
A B S T R A C T
This study assesses the differences in personal exposure to black carbon (BC) in the cabin of modern public buses in Stuttgart, Germany. We measured BC concentrations in four different seating locations, including priority seating locations, during rush hour and non-rush hour periods, and determined average exposures as well as the frequency of peak exposures. We hypothesize that the elderly and children (known to be more vulnerable to health impacts of air pollution) are exposed to higher concentrations as they are encouraged to make use of priority areas in proximity to doors in the middle of the bus, allowing for a greater flux of pollutants. We found no statistically significant difference in the mean BC concentrations between priority seating areas and other locations. However, a significant increase $(+32 \%)$ in the frequency of BC peaks ('spikes') was observed in one priority seating area when compared to the back of the bus. Furthermore, we found that travelling during rush hour was associated with significantly higher average in-vehicle BC concentrations in all seating locations compared with off peak hours $\left(1122 \mathrm{ng} / \mathrm{m}^{3}\right.$ or $38 \%$ higher), as well as a greater magnitude of the largest concentration spike of each trip $1295 \mathrm{ng} / \mathrm{m}^{3}$ (38\%). Further work may be necessary to refine most appropriate location for priority seating areas in buses and bus stops.
\end{abstract}

\section{Introduction}

Personal air pollution exposure in the transport microenvironment has received considerable attention over recent years (Rank et al., 2001, Boogaard et al., 2009, Dirks et al., 2012). In particular, pollution exposure while traveling using public transport can be up to 2-5 times higher than when at home or in urban background locations (Dons et al., 2012, Moreno et al., 2015). For illustration, one hour of travel in a 15-h day can contribute approximately a quarter of a person's daily average dose (Dons et al., 2012, Moreno et al., 2015). Importantly, many metropolitan areas are introducing policies to encourage the use of public transport for commuting (CIVITAS Initiative, 2013). Therefore, understanding pollution exposure in these environments is of importance (Lim et al., 2015). This is particularly true for public buses, as previous work has found that pollution exposure for bus passengers is considerably higher than for those travelling on trams and trains (Dons et al., 2012, Adams et al., 2001, Kaur et al., 2007).

One key pollutant associated with public transport is black carbon (BC). BC is a component of particulate matter (PM), specifically PM2.5 (particles $<2.5 \mu \mathrm{m}$ in aerodynamic diameter), and is almost exclusively emitted through the incomplete combustion of diesel. Both short- and long-term exposure to PM, including PM2.5 and BC, have been found to be associated with both increases in health problems and mortality (Knibbs et al., 2011; Knol et al., 2009; Ostro, 2016; Pope et al., 2002). Monitoring subjects during a

\footnotetext{
* Corresponding author at: Leiden University College, Leiden University, P.O. Box 13228, 2501 EE The Hague, The Netherlands.

E-mail address: p.a.behrens@luc.leidenuniv.nl (P. Behrens).
} 
two-hour walk down a busy road, Shinharay et al. (2017) found that relatively short-term exposure to BC and ultrafine particles in particular can be associated with changes in lung function and signs of arterial stiffness (especially if a person suffers from preconditions, in this case Chronic Obstructive Pulmonary Disease (COPD)). In particular, significant changes in forces expiratory volume in the first second $\left(\mathrm{FEV}_{1}\right)$ was seen within one to two hours following exposure. Further pointing to the harmful effect of $\mathrm{BC}$ particles (BCP), Janssen et al. (2011) suggest that "the estimated increase in life expectancy associated with a hypothetical traffic abatement measure was four to nine times higher when expressed in BCP compared with the equivalent change in PM2.5 mass". As such, "BCP more closely resembles the harmful components in these air pollution mixtures than does general PM2.5" (Janssen et al., 2011). The BC level is therefore considered to be a useful measure of exposure to road traffic emissions and its associated adverse health effects.

Previous work on pollution exposure on buses has focused on a variety of possible determinants to explain exposure to BC (Kingham et al., 2011; Knibbs et al., 2011; Liu et al., 2015). Overall, the rush hour period has been established as a significant predictor of in-vehicle concentrations of BC compared to other times of the day (Kaur et al., 2007; Dons et al., 2012). In addition, pollutant concentrations (both BC and PM2.5) can vary significantly during a single trip; door openings at bus stops are associated with peak exposures over a matter of minutes for UFP and various other sizes of PM (Lim et al., 2015; Tsai et al., 2008; Zhu et al., 2010; Moreno et al., 2015). There is evidence that both increased exposures over short, in the order of hours (Sinharay et al., 2017), medium, in the order of a day (Anderson et al., 2012) and well as long term are associated with adverse effects on health. Little is known about the very short-term effects (on the order of minutes) of exposure on health although short-terms peaks can contribute significantly to the mean concentrations over longer periods.

Here we investigate the air pollution exposure of public transport passengers on modern buses in Stuttgart, Germany. Stuttgart faces the highest air pollution concentrations among all cities nationwide (Sueddeutsche Zeutunge, 2016; Office for Environmental Protection, 2016), with policies now in place to increase the use of public transport and reduce the use of private vehicles (SSB, 2014). Importantly, vulnerable groups, including the young and elderly, are often overrepresented in public transport, including buses, due to their relative low rates of private vehicle access (Langlois et al., 2016). These vulnerable passengers are often seated near doors, as they are encouraged to make use of these priority seating areas, and therefore could be exposed to higher pollutant concentrations compared to other bus passengers. This is critical, since these vulnerable passengers, including children, the elderly, diabetics, and asthmatics, are more likely to suffer from increased cardiovascular complications and reduced lung function when exposed to transport pollutants compared with the general population (Laumbach et al., 2010; Morgenstern et al., 2007, Weichenthal et al., 2008; Kim et al., 2004).

To date only limited studies have focused on seating location as a determinant of exposure to PM. Hill et al. (2015) and Rim et al. (2008) measured $\mathrm{PM}_{2.5}$ and Ultra Fine Particle (UFP) counts in American school buses. They found that the influx of diesel fumes was generally related to the openings of the front door of the bus, resulting in higher average concentrations in the front of the bus compared to the middle section. A study on public buses, which have a different configuration compared to school buses, found that pollutant concentrations were around 2-7 times higher in the back of the bus than in the front (Vijayan and Kumar, 2010). Regardless of the outcomes, these studies show the importance of seating location on the exposures of those travelling by bus.

In this paper, we aim to fill a knowledge gap by investigating determinants of in-cabin BC concentrations on a modern public bus. We investigate several parameters of possible importance to the mean and peak BC exposures (of several minutes or less) in modern public buses including: seating location; rush hour; and door openings. Importantly, we specifically target the relative exposure of vulnerable groups, who are encouraged to make use of priority seating areas in the bus.

\section{Methods and data}

The study was conducted in Stuttgart (Germany) from 28th to 31st December 2015 between the times of 8:30AM to 7:30PM. A total of 36 trips were made, with each trip consisting of the same route through the city (Fig. 1). The route selected follows a main arterial road passing along a route frequently experiencing congested traffic conditions. In total, the route consists of 11 stops. The average (one-way) trip duration was around $15 \mathrm{~min}$, with each individual trip duration subject to the extent of traffic congestion at the time of data collection. Bus doors do not always open at every stop, but only open when required by passengers.

To reduce variation in pollutant concentrations attributable to bus configuration, the study was limited to one bus model, the 2007 Mercedes Benz CapaCity O 530 GL, running on diesel (Daimler AG, 2016). In addition to diesel, these buses are fueled with AdBlue (urea waste) to reduce the amount of nitrogen oxide in the exhaust. The city of Stuttgart increasingly employs these hybrid buses to help minimize emissions and hence pollutant concentrations in the inner-city basin, making them representative of the buses operating in the city. Measurement locations used within the bus can be seen in Fig. 2, and were in the front, back, middle-door, and middle-window. The middle-door, and middle-window locations are the two priority areas for vulnerable passengers on this model of bus. The bus model is fitted with air conditioning options, and has an electric ventilator system on the roof at the back of the bus.

Four MicroAeth AE51 units (AethLabs, San Francisco, USA) were used to monitor BC concentration at $10 \mathrm{~s}$ intervals, with a measurement error of $100 \mathrm{ng} / \mathrm{m}^{3}$ (AethLabs, 2016). The units were pre-calibrated, measuring near-identical concentrations of BC in a test setting. Therefore, no post hoc data adjustments were required. However, the units were rotated between the measurement locations each trip to avoid any systematic instrument bias that may have existed. Of the trips included, 17 were collected on the Monday, 10 on the Wednesday, and 9 on the Thursday. As this work was undertaken during a holiday period, the trips taken before 11:00 AM and after 4:00 PM were coded as rush hour while the remaining trips were coded as non-rush hour. Using this classification, 21 and 15 trips were taken during rush hour and non-rush hour, respectively.

To compare the impact of the predictors 'rush hour' and 'seating location' on the BC environment in the bus cabin, three analyses 


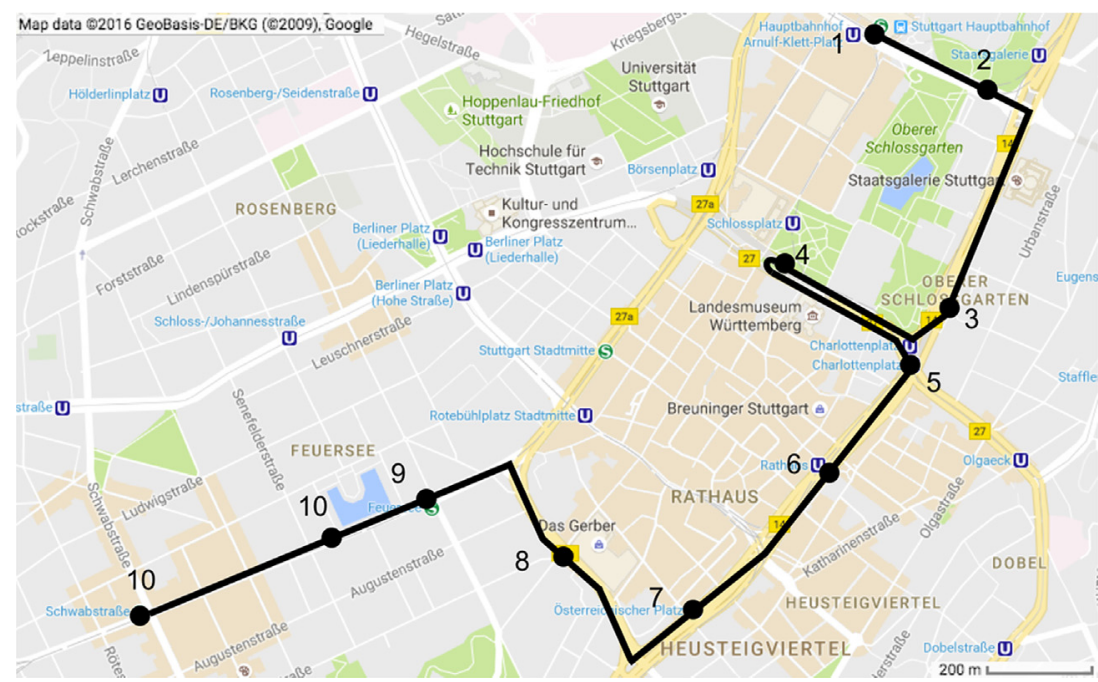

Bus Stops:

1 Hauptbahnhof

2 Staatsgalerie

3 Charlottenplatz

4 Schlossplatz

5 Dorotheenstrasse

6 Rathaus

7 Oesterreichischer Platz

8 Marienstrasse

9 Feuersee

10 Senefelderstrasse

11 Schwabstrasse

Fig. 1. Bus route and stops. The scale is visible in the bottom right corner of the figure.
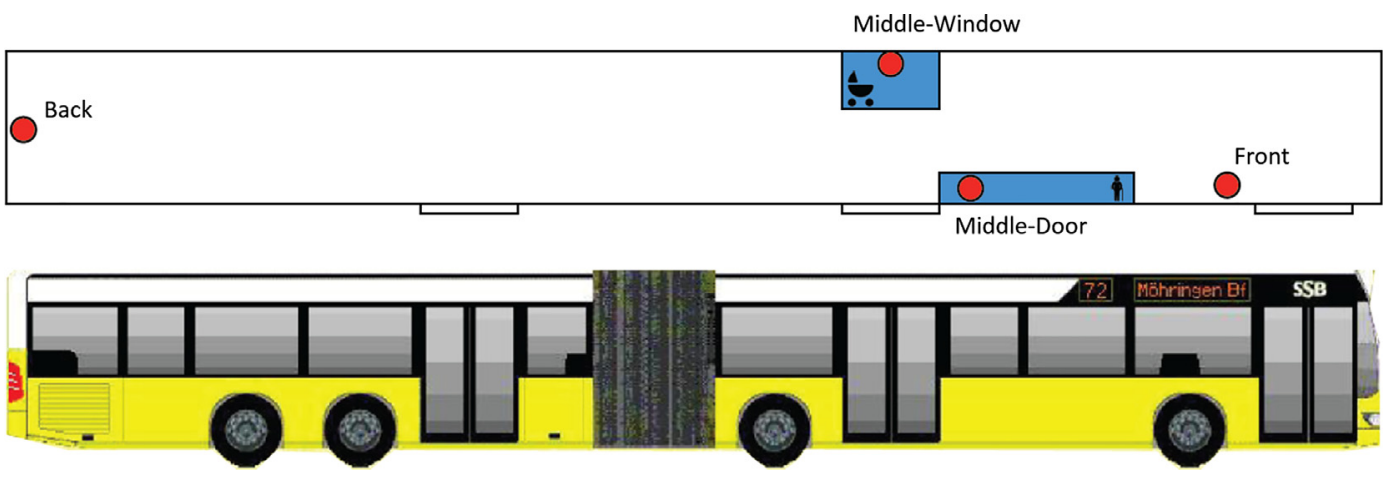

Fig. 2. Measurement locations inside the vehicle are indicated by the red circles. The priority seating areas are highlighted in blue.

were conducted: (i) comparisons of the mean BC concentrations, (ii) comparisons of the frequency of BC peaks, and (iii) comparisons of the magnitude of $\mathrm{BC}$ peaks.

Since the data are made up of instantaneous, time-series measurements that are not statistically independent, for the first analysis (mean BC concentrations), we averaged the BC concentrations per loop for each measurement device and compared the means. In the second analysis, we investigated the frequency of BC peaks, defined as peaks with concentrations above $300 \mathrm{ng} / \mathrm{m}^{3}$. Peak analysis was performed using the Matlab findpeaks script, specifying a minimum peak prominence above $300 \mathrm{ng} / \mathrm{m}^{3}$. Prominence is defined by 'how much a peak stands out due to its intrinsic height and location relative to other peaks' (see https://nl.mathworks.com/help/ signal/ref/findpeaks.html\#buff2t6 for further information). For ranges of peak prominence between 150 and $1500 \mathrm{ng} / \mathrm{m}^{3}$ findings discussed in the results section were robust, that is statistically significant. We hypothesise that this is reasonable since peaks lower than $150 \mathrm{ng} / \mathrm{m}^{3}$ are close to measurement precision of the devices $\left( \pm 100 \mathrm{ng} / \mathrm{m}^{3}\right.$ ), and peaks larger than $1500 \mathrm{ng} / \mathrm{m}^{3}$ were very unusual. Example peak analysis is shown in the results section in Fig. 3. In the third analysis, the same smoothed dataset and peak identification was used to calculate the mean peak magnitude for each location during each trip.

In addition, to understand the importance of door opening, the BC concentration before and after middle door openings at different bus stop locations were compared. The BC concentrations before and after door openings for 8 out of the 11 bus stops, shown in Fig. 2, were analysed. Two of the omitted bus stops were the start (Hauptbahnhof) and end (Schwabstrasse) of the bus route due to extended waiting times at these locations. The third omitted stop was Staatsgalerie since only the front door opened at this location. The differences were found by averaging the BC concentrations for $30 \mathrm{~s}$ before, and $30 \mathrm{~s}$ after opening of the middle door. The before and after concentrations were then analysed using a paired $t$-test for each location. There are some small, inset windows at the top of each larger window, which were open for some short periods. However, we were not able to find any significant influence of these openings on BC levels so these were ignored.

Statistical analyses were conducted using Matlab R2015b, with $\alpha \leq 0.05$. All data are reported as the mean \pm standard error (SEM). All data were checked for normality and homogeneity of variance to meet the assumptions before statistical analysis. If assumptions were violated and p-values were close to $\alpha$, this is highlighted in the text, as results need to be interpreted with caution. A two-way Analysis of Variance (ANOVA) was used for the first three analyses to investigate the impact of rush hour and seating 


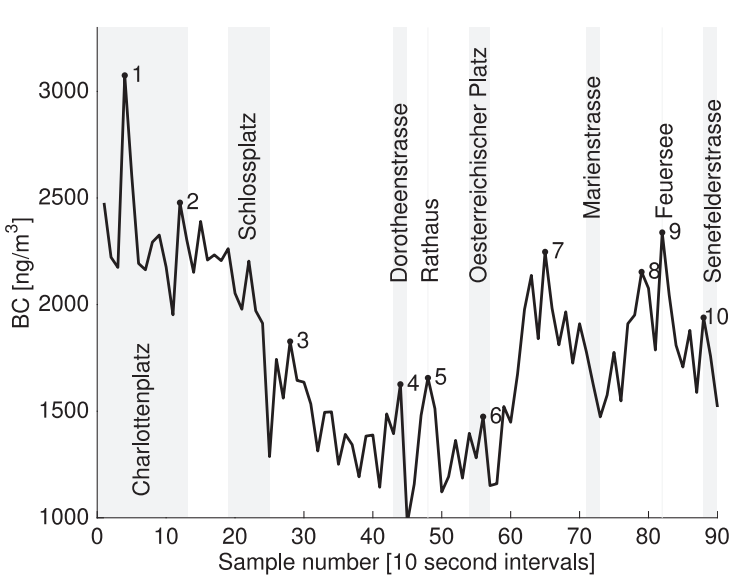

Fig. 3. The BC levels during a representative trip with door openings at the greatest number of stops. The BC levels plotted here are an average of the four locations on the bus. The grey regions show which bus stop location the doors were open for, and the duration of door opening. The round, numbered markers indicate the example peaks located in the data.

location, along with testing for interaction terms between the two. The impact of door-opening was done using a series of paired ttests for each location.

\section{Results}

The BC levels for a representative trip are shown in Fig. 3. The grey shaded areas show the door openings and duration for each stop. The BC levels are calculated as averages of all four locations on the bus. In general, it is possible to see the high levels of BC on the bus while the bus waits with the doors open for a long duration (see Charlottenplatz in Fig. 3 as an example). Subsequently, a reduction in cabin BC levels is seen at Schlossplatz, located next to a park and on a road with restricted traffic (further discussed below). Finally, the general trend of a minimum level at or after Schlossplatz, is then followed by increasing BC levels as the bus continues through the city centre (see sample numbers 40 and onwards in Fig. 3 as an example).

\subsection{Mean BC concentration}

There was no significant interaction found between rush hour and seating location on mean BC concentrations (two-way ANOVA, $\left.\mathrm{F}_{3136}=0.03, \mathrm{p}=0.99\right)$. The mean $\mathrm{BC}$ concentrations in both of the middle seating locations were on average $160 \mathrm{ng} / \mathrm{m}^{3} \mathrm{higher}$ compared to the other seating locations, but differences were not found to be statistically significant (two-way ANOVA, $\mathrm{F}_{3136}=0.16$, $\mathrm{p}=0.92$ ). However, there was a significant increase in BC concentration during rush hours compared to non-rush hours (two-way ANOVA, $\left.\mathrm{F}_{1136}=26.59, \mathrm{p}<0.001\right)$. On average, rush hour concentrations of BC were $1122 \mathrm{ng} / \mathrm{m}^{3}(38 \%)$ higher than during nonrush hours; further summary statistics are presented in Table 1.

\subsection{Frequency of peaks}

There was no significant interaction effect between rush hour and seating location on the frequency of BC peaks (two-way ANOVA, $\mathrm{F}_{1136}=1.27, \mathrm{p}=0.29$ ). However, the seating location did show a significant difference in the frequency of BC peaks (twoway ANOVA, $\mathrm{F}_{1136}=7.35, \mathrm{p}<0.001$ ). Post-hoc analysis revealed significant differences in the frequency of peaks between the back seat and the middle window seat (Tukey-Kramer $\mathrm{p}<0.05$ ). The number of peaks was $32 \%$ higher in the middle-window, priority

Table 1

Mean BC concentrations ( \pm SEM) during non-rush and rush hours for the four seating locations. All values are given in units of ng/ $\mathrm{m}^{3}$ along with the standard error of the mean, also in $\mathrm{ng} / \mathrm{m}^{3}$. Different letters a and $\mathrm{b}$ indicate significant differences between groups (two-way-ANOVA, $\mathrm{p} \leq 0.05$ ). For example, ' $\mathrm{a}$ ' and ' $\mathrm{b}$ ' here indicate that there is a significant difference between the average BC levels between rush, and non-rush hours.

\begin{tabular}{|c|c|c|c|}
\hline Seating location & $\begin{array}{l}\text { Non-rush } \\
{\left[\mathrm{ng} / \mathrm{m}^{3}\right]}\end{array}$ & $\begin{array}{l}\text { Rush } \\
{\left[\mathrm{ng} / \mathrm{m}^{3}\right]}\end{array}$ & $\begin{array}{l}\text { Average } \\
{\left[\mathrm{ng} / \mathrm{m}^{3}\right]}\end{array}$ \\
\hline Front & $2830 \pm 110$ & $3995 \pm 47$ & $3542 \pm 38$ \\
\hline Middle-door & $3013 \pm 107$ & $4180 \pm 47$ & $3726 \pm 38$ \\
\hline Middle-window & $2983 \pm 110$ & $4137 \pm 49$ & $3688 \pm 39$ \\
\hline Back & $2948 \pm 118$ & $3949 \pm 46$ & $3560 \pm 38$ \\
\hline Average & $2943 \pm 27 a$ & $4065 \pm 12 b$ & \\
\hline
\end{tabular}




\section{Table 2}

Frequency of BC peaks ( \pm SEM) during non-rush and rush hours for the four seating locations. All values are given in the number of peaks along with the standard error of the mean, also in the number of peaks. Different letters a and $b$ indicate significant differences between groups (two-way-ANOVA, $\mathrm{p} \leq 0.05$ ). For example, a and $\mathrm{b}$ here refer to significant differences in the frequency of $\mathrm{BC}$ peaks between the middle-window seat and all other seating positions.

\begin{tabular}{lll}
\hline Seating location & $\begin{array}{l}\text { Non-rush } \\
\text { [\# of peaks] }\end{array}$ & $\begin{array}{l}\text { Rush } \\
\text { [\# of peaks] }\end{array}$ \\
\hline Front & $13.14 \pm 0.32$ & $11.50 \pm 0.17$ \\
Middle-door of peaks] & $11.64 \pm 0.25$ & $11.09 \pm 0.15$ \\
Middle-window & $16.79 \pm 0.29$ & $13.82 \pm 0.22$ \\
Back & $11.14 \pm 0.24$ & $11.77 \pm 0.19$ \\
Average & $13.18 \pm 0.08$ & $12.05 \pm 0.05$ \\
\hline
\end{tabular}

seating area than at the back of the cabin, approximately below the roof ventilator. There were no further statistically significant differences. Rush hour showed some, weak indication of the frequency of peaks (two-way ANOVA, $\mathrm{F}_{1136}=2.77, \mathrm{p}<0.098$ ). Summary statistics are presented in Table 2.

\subsection{Magnitude of peaks}

There was no statistically significant interactive effect of rush hour and seating location on the peak magnitude of BC concentration (two-way ANOVA, $\mathrm{F}_{3136}=0.04, \mathrm{p}=0.99$ ). In addition, the seating location was not statistically significant with respect to the peak magnitude (two-way ANOVA, $\mathrm{F}_{3136}=0.32, \mathrm{p}=0.81$ ). During rush hour, the magnitude of the largest peak event for each trip was significantly higher compared to non-rush hours (two-way ANOVA, $\mathrm{F}_{1136}=27.03$, $\mathrm{p}<0.001$ ). On average, peak events were $1295 \mathrm{ng} / \mathrm{m}^{3}$ (38\%) higher during rush hour than during non-rush hours; further summary statistics are presented in Table 3.

\subsection{Influence of door opening}

While there are indications that mean differences do arise at some bus stops, i.e. that concentrations increase after door opening, these differences are not found to be statistically significant (Table 4). Only Schlossplatz shows a statistically significant change in BC concentration before and after door opening in the form of a reduction of $357 \mathrm{ng} / \mathrm{m}^{3}$. Schlossplatz is the only stop on the route not accessible to general traffic, and adjacent to a park (see Fig. 1).

\section{Discussion}

In this study, we found that the number of BC peak events during a bus trip in Stuttgart was significantly higher (on average 32\%) in a priority seating location in the middle of the cabin than at the back of the cabin. We also found that the mean BC concentration for trips conducted during rush hour were significantly higher (on average, $1122 \mathrm{ng} / \mathrm{m}^{3}$ higher) than those conducted during off-peak periods. This is consistent with the findings of Kaur et al. (2007) and Dons et al. (2012). Not only were average BC concentration higher during rush hour periods, but the peak concentrations observed during each trip were over twice as high during the peak compared to non-peak periods. Also, the magnitudes of the peaks were $38 \%$ higher during rush hour periods.

Although we saw some variation between seating location and BC concentrations (in both the mean and peak measurements), we did not find any statistically significant dependence. Interestingly, mean BC concentrations (see Table 1) were similar in the front and back of the bus during rush hour and slightly lower compared to the middle of the bus. Ventilation could have been higher in these locations as the air intake was located in the front of the CapaCity bus, and the rear was equipped with an electric roof ventilator (Daimler AG, 2016). Thus, although the front of the bus was a pollutant entry point due to door openings, the location of ventilation systems might have facilitated the quick dispersion of pollutants. This correspondence of levels in the front and back of the bus differs

Table 3

Magnitude of BC peak concentrations ( \pm SEM) during non-rush and rush hours for the four seating locations. All values are given in units of $\mathrm{ng} / \mathrm{m}^{3}$ along with the standard error of the mean, also in $\mathrm{ng} / \mathrm{m}^{3}$. Different letters a and $\mathrm{b}$ indicate significant differences between groups (two-way-ANOVA, $\mathrm{p} \leq 0.05$ ). For example, a and b here indicate that the magnitude of non-rush, and rush our peaks are statistically different.

\begin{tabular}{lll}
\hline Seating location & $\begin{array}{l}\text { Non-rush } \\
{\left[\mathrm{ng} / \mathrm{m}^{3}\right]}\end{array}$ & $\begin{array}{l}\text { Rush } \\
{\left[\mathrm{ng} / \mathrm{m}^{3}\right]}\end{array}$ \\
\hline Front & $3163 \pm 106$ & $4458 \pm 57$ \\
Middle-door & $3466 \pm 116$ & $4709 \pm 58$ \\
Middle-window & $3399 \pm 117$ & $4836 \pm 64$ \\
Back & $3468 \pm 129$ & $4673 \pm 61$ \\
Average & $3374 \pm 29 \mathrm{a}$ & $4669 \pm 15 \mathrm{~b}$ \\
\hline
\end{tabular}


Table 4

Statistical relationships for middle door opening locations (paired student $t$-test). The mean difference ( \pm SEM) is the average difference in $\mathrm{BC}$ concentration in the middle seat location averaged $30 \mathrm{~s}$ before, and averaged $30 \mathrm{~s}$ after door opening.

\begin{tabular}{llll}
\hline Bus stop location & $\mathrm{N}$ & $\begin{array}{l}\text { Mean difference } \\
{\left[\mathrm{ng} / \mathrm{m}^{3}\right]}\end{array}$ \\
\hline Charlottenplatz & & $405 \pm 105$ & $\mathrm{P}$ \\
Schlossplatz & 10 & $-357 \pm 11$ & $<.59$ \\
Dorotheenstrasse & 25 & $-20 \pm 79$ & $239 \pm 28$ \\
Rathaus & 7 & $11 \pm 15$ & 0.001 \\
Oesterreichischerplatz & 17 & $211 \pm 23$ & 0.13 \\
Marienstrasse & 25 & $231 \pm 28$ & 0.11 \\
Feuersee & 22 & $-18 \pm 53$ & 0.076 \\
Senefelderstrasse & 22 & 10 & \\
\hline
\end{tabular}

from other studies which, as described above, found significant differences between the two locations (for example Vijayan and Kumar (2010) and Hill et al. (2015)). Possible reasons for this is that previous studies have generally focused on older buses with less effective ventilation systems than the bus models investigated here. Additionally, there has been discussion in the literature regarding pollution arising from the bus itself, and there may be spatial differences in this self-pollution through the bus. In this work, we did not measure reliable levels of this pollution as the bus was always running throughout the route, even when in between trips. Levels for soot have been found to be $46 \%$ higher in diesel buses compared to electric buses (Zuurbier et al., 2010), similar to those found in other studies, albeit for older school buses in America (Adar et al., 2007, Behrentz et al., 2004). However, we did find that the frequency of events experienced by the middle-window location was significantly higher than the back-seat location. This may be explained by the proximity of this location to the large, middle door entrance. Our results suggest that once the doors have closed, the pollutants become well mixed within the cabin.

Finally, we investigated BC concentrations $30 \mathrm{~s}$ before and $30 \mathrm{~s}$ after door openings and found statistically significant differences (reductions in concentrations) at the Schlossplatz bus stop. This difference may have been particularly pronounced as it was the only stop not accessible to traffic and located in an open space within a park. While it is not possible to come to any firm conclusions on the basis of evidence from a single bus stop location, the findings nevertheless are consistent with those of Tallis et al. (2011) who identified green buffer-zones as being highly effective at reducing localized pollutant concentrations. Lim et al. (2015) highlight the detrimental impact of bus stop located in proximity to intersections. There is also some evidence to suggest that moving at least one stop away from the road to a less trafficked greener area can be expected to allow clean air to enter the bus cabin and reduce pollutant concentrations inside the bus. During the measurement period, bus driver changes occurred at a bus stop on a busier road (Charlottenplatz). Relocating this switch of drivers to the Schlossplatz bus stop could naturally introduce a longer stop at this location and could facilitate a better air exchange.

\section{Conclusions}

The results of this study suggest that the average BC exposure of passengers is not affected by seating location in the front, middle or at the back of the bus. However, the priority seating area in the middle of the bus is associated with a higher likelihood of experiencing a peak in concentration when compared to seating at the back of the bus. Secondly, those traveling during rush hour are subject to both higher mean concentrations as well as higher magnitudes and frequencies of BC peaks. Lastly, this study shows that the location of bus stops can play a significant role in reducing in-cabin concentrations.

It is important to note that the measurements were taken during vacation periods. Thus, differences in concentrations between rush and non-rush periods could be expected to be more pronounced during regular working time. Also, differences in bus patronage could also have affected bus ventilation and pollutant dispersion.

There is some evidence to suggest that bus route planning should consider moving one bus stop at least to one in proximity to urban greenery to allow for more effective pollutant outflow. Clear and reliable identification of the determinants of heightened invehicle concentrations could ensure that the shift to public transport is not only beneficial to the environment, but also that exposure of passengers to pollutants inside public transit buses is limited in order to avoid potential adverse health effects.

\section{Acknowledgments}

We would like to thank Geneeskundige Gezondheidsdienst, Amsterdam for the loan of the measurement devices over the period of this study and the Stuttgart transit system operators for allowing us to measure in the bus cabines. We would like to thank Joerg Bauer, Elke Bauer, Lisa Bauer, Antonia Bauer, Andreas Hensold, and Jana Rieth who aided in the data collection. We would also like to thank the three anonymous referees for their helpful comments and suggestions.

\section{Funding}

This research did not receive any specific grant from funding agencies in the public, commercial, or not-for-profit sectors. 


\section{Appendix A. Supplementary material} 009.

Supplementary data associated with this article can be found, in the online version, at http://dx.doi.org/10.1016/j.trd.2018.04.

\section{References}

Adams, H.S., Nieuwenhuijsen, M.J., Colvile, R.N., McMullen, M.A.S., Khandelwal, P., 2001. Fine particle personal exposure levels in transport microenvironments, London, UK. Atmos. Environ. 35, 4557-4566.

Adar, S.D., Gold, D.R., Coull, B.A., Schwartz, J., Stone, P.H., Suh, H., 2007. Focused exposures to air- borne traffic particles and heart rate variability in the elderly. Epidemiology 18, 95-103.

AethLabs, 2016. MicroAeth Model AE51: Operating Manual. AethLabs. San Francisco. Available: < https://aethlabs.com/microaeth/ae51/overview > (accessed 28/11/2016).

Anderson, J.O., Thundiyil, J.G., Stolbach, A., 2012. Clearing the air: a review of the effects of particulate matter air pollution on human health. J. Med. Toxicol 8, 166-175. http://dx.doi.org/10.1007/s13181-011-0203-1.

Behrentz, E., Fitz, D.R., Pankratz, D., Sabin, L.D., Colome, S.D., Fruin, S.A., Winer, A.M., 2004. Measuring self pollution in school buses using a tracer gas technique. Atmos. Environ. 38, 3735-3746.

Boogaard, H., Borgman, F., Kamminga, J., Hoek, G., 2009. Exposure to ultrafine and fine particles and noise during cycling and driving in 11 Dutch cities. Atmos. Environ. 43 , 4234-4242. http://dx.doi.org/10.1016/j.atmosenv.2009.05.035.

CIVITAS Initiative, 2013. About Us. CIVITAS: Cleaner and Better Transport in Cities. Available: < http://www.civitas-initiative.org/about-us-page > (accessed 28/11/2016).

Daimler AG, 2016. CapaCity L. The Standard of Buses. Available: < http://www.mercedes-benz.de/content/germany/mpc/mpc_germany_website/de/home_mpc/bus/home/ new_buses/models/regular_service_busses/capacity_e6.html\#_int_bus:home:model-navi:capacity_e6 > (accessed 28/11/2016).

Dirks, K.N., Sharma, P., Salmond, J., Costello, S.B., 2012. Personal exposure to air pollution for various modes of transport in Auckland, New Zealand. Open Atmos. Sci. J. 6, 84-92. http://dx.doi.org/10.2174/1874282301206010084.

Dons, E., Int Panis, L., Van Poppel, M., Theunis, J., Wets, G., 2012. Personal exposure to black carbon in transport microenvironments. Atmos. Environ. 55, 392-398. http://dx. doi.org/10.1016/j.atmosenv.2012.03.020.

Hill, L.B., Zimmerman, N.J., Gooch, J., 2015. A multi-city investigation of the effectiveness of retrofit emissions controls in reducing exposures to particulate matter in school buses. Clean Air Task Force Report. Available: < http://www.catf.us/resources/publications/files/CATF-Purdue_Multi_City_Bus_Study.pdf > (accessed 28/11/2016).

Janssen, N.H., Hoek, G., Simic-Lawson, M., Fischer, P., van Bree, L., ten Brink, H., et al., 2011. Black carbon as an additional indicator of the adverse health effects of airborne particles compared with $\mathrm{PM}_{10}$ and $\mathrm{PM}_{25}$. Environ. Health Perspect. 119, 1691-1699. http://dx.doi.org/10.1289/ehp.1003369.

Kaur, S., Nieuwenhuijsen, M.J., Colvile, R.N., 2007. Fine particulate matter and carbon monoxide exposure concentrations in urban street transport microenvironments. Atmos. Environ. 41, 4781-4810. http://dx.doi.org/10.1016/j.atmosenv.2007.02.002.

Kim, J.J., Smorodinsky, S., Lipsett, M., Singer, B.C., Hodgson, A.T., Ostro, B., 2004. Traffic-related air pollution near busy roads: the east bay children's respiratory health study. Am. J. Respir. Crit. Care Med. 170, 520-526. http://dx.doi.org/10.1164/rccm.200403-2810C.

Kingham, S., Pattinson, W., Shrestha, K., Longley, I., Salmond, J., 2011. Determination of personal concentration to traffic pollution while traveling by different modes, vol. 457. New Zealand Transport Agency Research Report. Available: < http://www.nzta.govt.nz/assets/resources/research/reports/457/docs/457.pdf > (accessed 28/11/2016).

Knibbs, L.D., Cole-Hunter, T., Morawska, L., 2011. A review of commuter exposure to ultrafine particles and its health effects. Atmos. Environ. 45, $2611-2622$.

Knol, A.B., de Hartog, J.J., Boogaard, H., Slottje, P., van der Sluijs, J.P., Lebret, E., et al., 2009. Expert elicitation on ultrafine particles: likelihood of health effects and causal pathways. Part. Fibre Toxicol. 6, 19. http://dx.doi.org/10.1186/1743-8977-6-19.

Langlois, G., Koutsopoulos, H.N., Zhao, J., 2016. Inferring patterns in the multi-week activity sequences of public transport users. Transp. Res. Part C Emerg. Technol. 64, 1-16. http://dx.doi.org/10.1016/j.trc.2015.12.012.

Laumbach, R.J., Rich, D.Q., Gandhi, S., Amorosa, L., Schneider, S., Zhang, J., et al., 2010. Acute changes in heart rate variability in subjects with diabetes following a highway traffic exposure. J. Occup. Environ. Med. 52, 324-331. http://dx.doi.org/10.1097/JOM.0b013e3181d241fa.

Lim, S., Dirks, K.N., Salmond, J.A., Xie, S., 2015. Determinants of spikes in ultrafine particle concentration whilst commuting by bus. Atmos. Environ. 112, 1-8. http://dx.doi.org/ 10.1016/j.atmosenv.2015.04.025.

Liu, W.T., Ma, C.M., Liu, I.J., Han, B.C., Chuang, H.C., Chuang, K.J., 2015. Effects of commuting mode on air pollution exposure and cardiovascular health among young adults in Taipei, Taiwan. Int. J. Hyg. Environ. Health 218, 319-323. http://dx.doi.org/10.1016/j.ijheh.2015.01.003.

Moreno, T., Reche, C., Rivas, I., Cruz Minguillón, M., Martins, V., Vargas, C., et al., 2015. Urban air quality comparison for bus, tram, subway and pedestrian commutes in Barcelona. Environ. Res. 142, 495-510. http://dx.doi.org/10.1016/j.envres.2015.07.022.

Morgenstern, V., Zutavern, A., Cyrys, J., Brockow, I., Gehring, U., Koletzko, S., et al., 2007. Respiratory health and individual estimated exposure to traffic-related air pollutants in a cohort of young children. Occup. Environ. Med. 64, 8-16. http://dx.doi.org/10.1136/oem.2006.028241.

Office for Environmental Protection, 2016. Luft: Erfolgreiche Massnahmen zur Luftreinhaltung. Stuttgart. Available: < http://www.stuttgart.de/item/show/15638 > (accessed $28 / 11 / 2016)$

Ostro, B., 2016. Outdoor Air Pollution: Assessing the Environmental Burden of Disease at National and Local Concentration. World Health Organization Environmental Burden of Disease Series. Available: < http://www.who.int/quantifying_ehimpacts/publications/ebd5.pdf > (accessed 28/11/2016).

Pope III, C.A., Burnett, R.T., Thun, M.J., Calle, E.E., Krewski, D., Thurston, G.D., 2002. Lung cancer, cardiopulmonary mortality, and long-term exposure to fine particulate air pollution. J. Am. Med. Assoc. 287, 1132-1141. http://dx.doi.org/10.1001/jama.287.9.1132.

Rank, J., Folke, J., Jespersen, P. Homann, 2001. Differences in cyclists and car drivers exposure to air pollution from traffic in the city of Copenhagen. Sci. Total Environ. 279, 131-136. http://dx.doi.org/10.1016/S0048-9697(01)00758-6.

Rim, D., Siegel, J., Spinhirne, J., Webb, A., McDonald-Buller, E., 2008. Characteristics of cabin air quality in school buses in Central Texas. Atmos. Environ. 42, 6453-6464. http://dx.doi.org/10.1016/j.atmosenv.2008.04.030.

SSB, 2014. Geschaeftsbericht: Stuttgarter Strassenbahnen AG. Stuttgarter Strassenbahnen AG. Available: < http://www.ssb-ag.de/files/ssb_geschaeftsbericht_2014_kleine_ dateigroesse rz neu.pdf $>$ (accessed 28/11/2016).

Sueddeutsche Zeutung, 2016. Stuttgart loest als erste Stadt in Deutschland den Feinstaubalarm aus. Sueddeutsche Zeitung. Available: < http://www.sueddeutsche.de/panorama/ luftverschmutzung-stuttgart-loest-als-erste-stadt-in-deutschland-feinstaubalarm-aus-1.2822775 > (accessed 28/11/2016).

Sinharay, R., Gong, J., Barratt, B., et al., 2017. Respiratory and cardiovascular responses to walking down a traffic-polluted road compared with walking in a traffic-free area in participants aged 60 years and older with chronic lung or heart disease and age-matched healthy controls: a randomised, crossover study. The Lancet. http://dx.doi.org/10. 1016/s0140-6736(17)32643-0.

Tallis, M., Taylor, G., Sinnett, D., Freer-Smith, P., 2011. Estimating the removal of atmospheric particulate pollution by the urban tree canopy of London, under current and future environments. Landsc. Urban Plan 103, 129-138. http://dx.doi.org/10.1016/j.landurbplan.2011.07.003.

Tsai, D.H., Wu, Y.H., Chan, C.C., 2008. Comparisons of commuter's exposure to particulate matters while using different transportation modes. Sci. Total Environ. 405, 71-77. http://dx.doi.org/10.1016/j.scitotenv.2008.06.016.

Vijayan, A., Kumar, A., 2010. Experimental and statistical analyses to characterize in-vehicle fine particulate matter behavior inside public transit buses operating on B20-grade biodiesel fuel. Atmos. Environ. 44, 4209-4218. http://dx.doi.org/10.1016/j.atmosenv.2010.07.012.

Weichenthal, S., Dufresne, A., Infante-Rivard, C., Joseph, L., 2008. Determinants of ultrafine particle exposures in transportation environments: findings of an 8-month survey conducted in Montréal, Canada. J. Expo. Sci. Environ. Epidemiol. 18, 551-563. http://dx.doi.org/10.1038/sj.jes.7500644.

Zhu, S., Demokritou, P., Spengler, J., 2010. Experimental and numerical investigation of micro-environmental conditions in public transportation buses. Build. Environ. 45, 2077-2088. http://dx.doi.org/10.1016/j.buildenv.2010.03.004.

Zuurbier, M., Hoek, G., Oldenwening, M., Lenters, V., Meliefste, K., van den Hazel, P., Brunekreef, B., 2010. Commuters' concentration to particulate matter air pollution is affected by mode of transport, fuel type, and route. Environ. Health Perspect. 118 (6), 783-789. 